review

\title{
Genes, Race, and the Ethics of Belief
}

\author{
by Jonathan Anomaly
}

1 Troublesome Inheritance, by Nicholas Wade, should be read by anyone interested in race and recent human evolution. Wade deserves credit for challenging the popular dogma that biological differences between groups either don't exist or cannot explain the relative success of different groups at different tasks. Wade's work should be read alongside another recent book, The 10,000 Year Explosion: How Civilization Accelerated Human Evolution, by Gregory Cochran and Henry Harpending.

Together these books represent a major turning point in the public debate about the speed with which relatively isolated groups can evolve: both books suggest that small genetic differences between members of different groups can have large impacts on their abilities and propensities, which in turn affect the outcomes of the societies in which they live. Ever since the 1950s, Wade argues, many academics have denied the biological reality of race, and some have suggested that merely believing in racial differences constitutes a kind of racism. But the rejection of race as a useful concept is often more of a political pose than a serious scientific claim, and it became especially popular among academics after the Second World War, during which Nazi pseudoscientists used claims of racial superiority to justify mass murder.

As it turns out, Ashkenazi Jews—generally, those Jews with roots in Russia, Poland, and Germany, the group nearly exterminated in the Holocaust-have been consistently found by intelligence researchers to have the highest average IQ in the world. The 10,000 Year Explosion and $A$ Troublesome Inheritance each spend an entire chapter detailing the remarkable achievements of Ashkenazi Jews and hold them up as exhibit A in the argument that human evolution has been, in Wade's words, recent, copious, and regional. The example of Ashkenazi evolution is supposed to show the absurdity of the view, held by authors like Jared Diamond and Stephen Jay Gould, that human evolution either stopped one hundred thousand years ago or that natural selection has somehow continued to sculpt the bodies but not the brains of different groups of people.

Wade uses "race" to refer to groups of people who have been separated long enough to have developed clusters of functionally significant genetic differences, and "ethnicity" to apply to groups within races who have small but significant genetic differences from other groups within a race. The concept of an ethnicity is made especially clear if we understand the coevolution of genes and culture. If within a culturally diverse but racially distinctive region like the Arabian Peninsula, nomadic Bedouins tend to marry Bedouins, while city dwellers marry each other, then Bedouins and city dwellers may begin to diverge into biologically and culturally different ethnicities as they face different selective pressures. For example, because Bedouins were nomads who increasingly depended on their camels for transportation and milk, those who produced the lactase enzyme (which facilitates milk digestion) into adulthood had a reproductive advantage over those who lacked this enzyme. As the allele for lactose tolerance spread through the population, reliance on camels became even more entrenched in Bedouin culture, and selective pressure increased for lactose tolerance. Despite being both Arab and Muslim, Bedouins have enough genetic and cultural differences to constitute a distinctive ethnic group throughout the Middle East. The important point is that cultural pressures can directly impact natural selection, and preexisting traits create propensities that shape culture. Wade ultimately invokes gene-culture coevolution to explain, among other things, how $\mathrm{Ti}^{-}$ betans evolved a greater capacity to tolerate life in the mountains than Indians, how Europeans who have depended on agriculture for thousands of years can consume more carbohydrates without succumbing to diabetes than Native Americans, and how Ashkenazi Jews could have evolved higher intelligence than Sephardic Jews in as little as one thousand years.

Wade uses terms like "race" and "ethnicity" in a deliberately vague way, as shorthand for saying that there are relatively large or small genetic differences between groups of people-differences that are path dependent and arise from breeding within a discrete population. $\mathrm{He}$ also concedes that racial groups are separated by fuzzy borders rather than sharp lines. This is because of genetic exchange between groups and because most alleles are merely distributed with different frequencies in different populations (not all Bedouins, for example, are lactose tolerant).

If scientists can uncover the genetic basis of group differences, shouldn't we worry that the study of race will promote racism? Wade takes this question up in the first and last chapters of the book, although his answers are only partially convincing. First, he says, racial differences are not all that big: "People

A Troublesome Inheritance: Genes, Race and Human History. By Nicholas Wade. Penguin, 2014. 288 pages. Hardcover. \$27.95. 
being so similar, no one has the right or reason to assert superiority over a person of a different race" (p. 9). While it is true that most genetic differences between groups are not large, this is less convincing than the analogous argument from individual differences. Wade should have said, "Individual people being so different, no one has the right or reason to assert superiority over a person of a different race." This is because there is tremendous genetic variation between individuals within a particular race, sometimes more than the average variation across races. Even if the average Asian has an IQ of 105 and the average African has an IQ of 90, two individual Asians may have an IQ of 120 and 80, respectively (it is important to separate genetic and environmental contributions to IQ and to note that IQ does not capture every aspect of intelligence, but assume for the moment that we are speaking only about the genetic component of IQ).

The problem with saying that "Asians are smarter than Africans" or that "Africans are faster than Asians" is not simply that differences between groups are not very large. It's rather that, in any given case, there is a good chance that the assertion is factually incorrect, because of the bell-shaped distribution of traits like memory or muscle mass within a population. By contrast, the problem with saying that "Africans are superior to Asians" is that there is no widely agreed upon set of characteristics that composes "superiority." Computational skills and running speed are only some of the many things people care about. Compassion and kindness, creativity, aesthetic beauty, and a sense of humor are among the many other qualities people prize. Although a truly exceptional individual may possess more of these traits than another individual, no race or ethnicity possesses all or even most of them more than other races. And in a market society characterized by specialization and exchange, everyone benefits from the different talents of everyone else.

Wade's second argument, more convincing than the first, is that claims about racial superiority are normative claims that cannot be undermined by appeals to group differences. Wade doesn't spend much time on this, but he does say that "the notion that any race has the right to dominate others or is superior in any absolute sense can be firmly rejected as a matter of principle and, being rooted in principle, is unassailable by science" (p. 8).

This is not to say that Wade's book is unproblematic. Some of his more provocative hypotheses have the potential to comfort racists who wish to explain the relative success of different groups via biology alone rather than institutions. Wade is surely right that biological differences can create the preconditions for some institutions to succeed or fail, but he often pushes the argument well beyond what the evidence can support. For example, he ignores the role of fossil fuels in providing the cheap energy that facilitated English economic growth in the nineteenth century and concentrates instead on the role of the eugenic effects of the English social structure that preceded the Industrial Revolution.

In discussing how differences in gene-culture coevolution can explain the trajectory of different groups, Wade argues that as hunter-gatherers moved into settled communities, changes occurred in certain genetically mediated traits, including a capacity to trust more people and a greater willingness to defer to impersonal social norms and punish norm-violators. This seems plausible enough, and it may explain why it took so long for humans to move from small and mobile hunter-gatherer societies to large and settled agricultural societies. But it has a troubling implication. Wade thinks that some groups of people, including modern hunter-gatherers and their recent descendants, will have a hard time living in modern nation states - not merely because they are accustomed to a different way of life, but because they are genetically ill-suited to live under alternative institutions.

It is hard to know what to make of claims like this, especially without more knowledge of how genes mediate social behaviors. Although Wade cites studies that suggest that some groups have greater frequencies of alleles associated with violence and that hunter-gatherers who are more successful at violent warfare are often rewarded with more offspring, he warns his readers that he is going well beyond what the available evidence demonstrates and offering conjectures about why some groups have prospered under modern social and political institutions, while others have not.

These claims raise compelling questions about the ethics of belief, as well as the justification of belief. For example, if some stereotypes turn out to have a biological basis, will this reduce our ability to treat each other fairly? It is not always unfair to use information about biological differences to make generalizations (for example, that men are more prone to violence than women or that West Africans are more prone to sickle cell anemia than East Africans), but sometimes information-even if it is accurate-can be used by some people to unfairly dominate others. Wade's speculation would be innocuous if it weren't likely to be read by people who will misinterpret it or use it to justify racist attitudes or policies. Assuming it is likely to be misunderstood or misused by some people, the question is whether such speculation should be part of a public discussion. As academics, we should follow the arguments wherever they lead us and pursue the truth even when it challenges our most cherished beliefs. As citizens, we should worry that arguments like Wade's will be used by demagogues to prey on people who are prone to fantasies about racial purity. The trick for thoughtful readers is to separate science from speculation and to highlight the difficulty of deriving normative conclusions from empirical claims.

DOI: $10.1002 /$ hast.358 